\title{
Discharge measurement with salt dilution method in irrigation canals: direct sampling and geophysical controls
}

\author{
C. Comina ${ }^{1}$, M. Lasagna ${ }^{1}$, D. A. De Luca ${ }^{1}$, and L. Sambuelli ${ }^{2}$ \\ ${ }^{1}$ Dept. of Earth Science (DST), Università degli Studi di Torino, via Valperga Caluso, 35, \\ 10125, Italy \\ ${ }^{2}$ Dept. of Environment, Land and Infrastructure Engineering (DIATI), Politecnico di Torino, \\ corso Duca degli Abruzzi, 24, 10129, Italy
}

Received: 22 June 2013 - Accepted: 15 July 2013 - Published: 1 August 2013

Correspondence to: C. Comina (cesare.comina@unito.it)

Published by Copernicus Publications on behalf of the European Geosciences Union.

10035

\begin{abstract}
An important starting point for designing management improvements, particularly in irrigation areas, is to record the baseline state of the water resources, including the amount of discharge from canals. In this respect discharge measurements by means 5 of the salt dilution method is a traditional and well-documented technique. However, this methodology can be strongly influenced by the natural streaming characteristics of the canal (e.g. laminar vs. turbulent flow) and accurate precautions must be considered in the choice of both the measuring section and the length of the measuring reach of the canal which can affect the plume shape. The knowledge of plume distri-

10 bution in the measuring cross-section is of primary importance for a correct location of sampling points aimed in obtaining a reliable measurement. To obtain this, geophysical imaging of an $\mathrm{NaCl}$ plume from a slug-injection salt dilution test has been performed within this paper by means of cross-flow fast electric resistivity tomography (FERT) in a real case history. Direct sampling of the same plume has been also performed with

15 a multisampling optimization technique to obtain an average value over the measuring section by means of contemporarily sampling water in nine points. Results show that a correct visualization of the passage of the salt plume is possible by means of geophysical controls and that this can potentially help in the correct location of sampling points.
\end{abstract}

\section{Introduction}

Improved management of water resources is becoming more and more important as several areas of the world suffer from water shortages. An important starting point for designing management improvements is to record the baseline state of the resources, including the amount of discharge from watercourses. Discharge is therefore an important property and is frequently monitored along many of the major rivers, streams and canals. Discharge measurement by means of injection of a $\mathrm{NaCl}$-solution and 
integration of the electrical conductivity $(E C)$ as a function of time is a traditional and well-documented method (salt dilution method). Alternatives for a precise discharge measurement may be the use of a current meter or the float method (Kalbus et al., 2006). The salt dilution technique is, however, the mostly used method in open chan5 nels in investigating superficial flows, especially in remote mountainous or difficult to access areas where it can be hard to establish an high quality hydrologic profile, and even harder to measure actual flow speed (Radulović et al., 2008).

Within the salt dilution method, constant-rate injection of salt is best suited for small streams at low flows (discharges less than about $0.1 \mathrm{~m}^{3} \mathrm{~s}^{-1}$ ), conversely slug injec10 tion can be used to gauge flows up to $10 \mathrm{~m}^{3} \mathrm{~s}^{-1}$ or greater, depending upon channel characteristics (Moore, 2005).

A limit of the salt dilution method is the amount of tracer to be added to increase the conductivity at the peak of the tracer flow-through curve. This is mainly linked to the background level of the conductivity: if this is less than $100 \mu \mathrm{Scm}^{-1}$ a smaller amount

15 of salt per $\mathrm{m}^{3}$ of runoff can be added; otherwise if the background conductivity is more than $500 \mu \mathrm{S} \mathrm{cm}^{-1}$, more than $5 \mathrm{~kg}$ of salt per $\mathrm{m}^{3}$ should be used (Gees, 1990). However, given this limitation, an advantage of the method is that the measuring equipment is very easy to move. The salt can be dissolved on site in a vessel (bucket, barrel) and it can be directly poured from it. In this respect slug injection is more commonly used, as

20 it requires no additional equipment. A disadvantage of this method is that only a runoff less than $4 \mathrm{~m}^{3} \mathrm{~s}^{-1}$ can be made easily, because the amount of salt to be dissolved is difficult to handle (about $20 \mathrm{~kg}$ of salt for $4 \mathrm{~m}^{3} \mathrm{~s}^{-1}$ runoff) (Gees, 1990).

Under suitable conditions, streamflow measurements made by slug injection can be precise within about $\pm 5 \%$ (Day, 1976). However, tracer-dilution method requires

25 a complete vertical and lateral mixing at the sampling site that needs to be assessed, particularly in linear irrigation canals, like in the present case study. Vertical mixing is usually accomplished very rapidly compared to lateral mixing (Rantz, 1982). Frequently, long reaches are needed for complete lateral mixing of the tracer. The mixing distance will vary however also with the hydraulic characteristics of the reach (e.g.

10037

laminar vs. turbulent flow). When the slug injection method is used, complete mixing is considered to have occurred when the area under the concentration-time curve has the same value at all points in the downstream sampling section (Rantz, 1982). Generally, an optimum mixing length is the one that produces mixing adequate for an accurate 5 discharge measurement but does not require an excessively long duration of sampling. If adequate mixing is known to exist at a given sampling site, the tracer cloud in the slug injection method must be sampled for its entire time of passage (from the time of its first appearance until the time of its disappearance) at several locations throughout the sampling cross section of the channel (Rantz, 1982). Experience indicates that regard-

10 less of method or stream size, at least three lateral sampling points should be used at each sampling site (Rantz, 1982).

Alternatively, to obtain a direct visualization of the tracer plume and then a proper location of the monitoring points, indirect geophysical measurements could be used, aimed at imaging the passage of the $\mathrm{NaCl}$ solution in the monitored section. In this

15 respect process tomography, in the forms of electrical resistivity tomography (ERT) has been developed in the last decades of the 20th century as a tool for monitoring biphase or multi-phase mixtures flows in numerous applications (Xie et al., 1995; Tapp and Wilson, 1997). Tomographic methods, and their interpretation based on the electrical properties of water mixtures, are appealing in numerous applications since they

20 can be used, for example, to image component concentration distributions and detect transient dynamic changes in multi-phase processes. Moreover they can also give quantitative evaluations about the properties of imaged mixtures. In this respect various relationships can be found in the literature relating the electrical resistivity to the physico-chemical properties of the mixture.

25 Most of the applications of this technique (Fangary et al., 1998; Lucas et al., 1999; Wang and Cilliers 1999; Yang and Liu 2000; Warsito and Fan, 2001) deal with cylindrical flows bodies (in pipes, cyclones, tanks) and the electrodes are placed on one or more circumferences orthogonal to the cylinder axis. This geometrical configuration assures an optimum conditioning of the inverse tomographic problem but however 
limits its applicability to real case studies on natural rivers or channels. Some previous studies have been already carried out assessing the possibility of recognising the presence of granular materials in slow water flows (Sambuelli et al., 2002) and in imaging solid and pollutants transport characteristics in fast water flows (Sambuelli and Comina,

5 2010) in situations where the imaged body cannot be entirely surrounded by electrodes as in the case of creeks, rivers and canals.

The objective of this study is therefore to evidence the real distribution of a $\mathrm{NaCl}$ plume from a slug-injection salt dilution test in a test cross section, by means of crossflow fast electric resistivity tomography (FERT), and to evaluate the effect that a non

10 uniform tracer cloud could have on an incorrect location of the monitoring points in the cross section. In this respect the application of the same technique presented in Sambuelli and Comina (2010) is reported in a real case history in order to monitor the salt plume used for discharge measurement with the salt dilution method in slug injection approach. A sampling optimization in the downstream sampling section was also

15 tested, sampling the canal water in different points of the cross section, and obtaining an average value over the sampled area by means of a contemporary water picking up.

\section{Material and methods}

After a brief introduction on the test site, the conceptual basis and field procedures for slug injection using salt dilution method and geophysical controls are hereafter ex-

20 posed. Particularly the water multi-sampling system, proposed for the optimization of the tracer quantitative detection, is described together with the field procedures necessary for the execution of electric tomographies.

\subsection{The study area: the Osasco Canal}

The Osasco Canal is an irrigation canal located in Piedmont (north-western Italy). It 25 has an overall length of about $7 \mathrm{~km}$ and carries water from the Chisone River (Fig. 1).

10039

The investigated canal reach, in which direct measurements and geophysical controls were made, has a length of about $100 \mathrm{~m}$, an average width of $2 \mathrm{~m}$ and about 0.5 water level. The Osasco Canal has a gross average discharge of $0.5 \mathrm{~m}^{3} \mathrm{~s}^{-1}$, estimated with a current meter, and a water EC of about $170 \mu \mathrm{Scm}^{-1}$ (Clemente et al., 2013; Perotti 5 et al., 2013).

Some pictures of both the sampling and the injection points are reported in Fig. 2. In this portion the bottom of the channel is cobbled (gravels and cobbles) and cement less except for a small portion immediately upstream of the chosen injection point, where a small cemented weir is located (Fig. 2). The measuring section is located under a small road bridge and a canal curve is placed immediately downstream of this section (Fig. 2). A part from injection and measuring sections the canal is difficult to access due to dense vegetation growing on the banks.

\subsection{Canal reach choice}

Following precautions for the salt dilution method, the most appropriate canal reach 15 has been selected for the execution of the tests (Figs. 1 and 2) considering that:

a. the reach should not have dead water between the injection and sampling points: the storage and slow release of tracer from those areas greatly prolongs the time required to the entire salt cloud to pass at the sampling site;

b. the sampling site has to be free of excessive turbulence; indeed EC measurements are adversely affected by the presence of air bubbles (Fig. 2);

c. an injection point that is turbulent enough to ensure virtually instantaneous mixing is to be chosen; this condition is not always easy to be achieved especially in irrigation canals where laminar flow can be predominating (Fig. 2);

d. the background EC level of the river is to be stable during the measuring time;

e. it is important to identify an optimum mixing length for a given canal reach; too short distances will result in an inaccurate accounting of the tracer mass passing 
the sampling site, conversely, too great a distances will yield excellent results, but only if it is feasible to sample for a long enough period (Rantz, 1982).

\subsection{Slug injection method with sampling optimization}

The slug injection method required the instantaneous injection of a slug of tracer solu5 tion and the accounting of the total mass of tracer at the sampling cross section. Common salt $(\mathrm{NaCl})$ was used as tracer; it is the most frequently used chemical tracer and provides the best results (Drost, 1989; Kumar and Nachiappan, 2000; Tazioli, 2011). It indeed meets all the criteria for a tracer: is (a) "chemically conservative", i.e., does not adsorb ("chemically bind") onto river sediments, (b) has a high solubility in water, (c) is

10 relatively non-toxic, (d) can be measured in the field indirectly with a conductivity meter, and (e) is relatively cheap and readily available. In this study a $\mathrm{NaCl}$ mass of $9 \mathrm{~kg}$ was dissolved in a barrel within about $30 \mathrm{~L}$ of water and this slug was instantaneously injected into the canal at the injection point (Fig. 2).

The slug of tracer solution instantaneously injected into the canal produced

15 a concentration-time curve in the downstream sampling cross section. Given this experimental curve the equation for computing stream discharge, which is based on the principle of the conservation of mass, is (Rantz,1982):

$Q=\frac{V_{0} \cdot C_{0}}{\int_{0}^{\infty}\left(C-C_{\mathrm{b}}\right) \mathrm{d} t}$

where $Q$ is the discharge of the canal, $V_{0}$ is the volume of the tracer solution injected 20 into the canal, $C_{0}$ is the concentration of this solution, $C$ is the measured tracer concentration at a given time at the downstream sampling site and $C_{\mathrm{b}}$ is the background concentration of the canal.

The term $\int_{0}^{\infty}\left(C-C_{\mathrm{b}}\right) \mathrm{d} t$ globally represents the total area under the concentrationtime curve. To experimentally obtain this curve, the passage of the entire tracer cloud 25 was monitored by continuously measuring the EC value of the channel water at the

10041

sampling section, to determine the relationship between EC and time. The elapsed time between subsequent measures of EC was $5 \mathrm{~s}$. The basic principles is that the ion concentration of the slug injected increases the natural water concentration, $(C-$ $C_{\mathrm{b}}$ ) can be viewed as an "incremental" concentration with respect to the background, 5 consequently increases also the measured electrical conductivity which can be used as an index of the salt concentration. Indeed, over a wide range of concentrations the EC is directly proportional to salt concentration (Radulović et al., 2008; Moore, 2005; Gees, 1990; Rantz, 1982). The recorded values of EC were then transformed into concentration values through the use of a laboratory estimated calibration line. This

10 calibration was constructed measuring the variation of EC in the water canal to the addition of different amounts of $\mathrm{NaCl}$. In this way the "incremental concentration" in respect to the natural water conductivity, which is used as reference, is obtained. The example calibration line for the present study is reported in Fig. 3.

Tracer-dilution measurements require a complete tracer mixing at the sampling site.

15 However, the detection of the tracer is often performed in only one point, normally central to the sampling cross section. This procedure can create some mistakes in the calculation of canals discharge if the injection solution is not fully mixed across the channel at the downstream sampling section.

In order to make the EC values more representative of the entire sampling cross

20 section and to obtain the optimization of quantitative detection, a water multi-sampling system was devised. This system was realized by means of a framework of steel rods to which 9 tubes of small diameter are connected. The tubes are linked to a water pump which spills the water of the canal simultaneously from the 9 measuring points. The objective of this apparatus is to allow for a more uniformly distributed sampling points 25 through the whole section of the canal; however due to the accessibility of the measured section (different water depths along it) and to the manoeuvrability of the whole system, only a portion of the section has been sampled. A scheme of the adopted multi-sampling system and of its location is reported in Fig. 4. 


\subsection{Cross-flow FERT}

Cross-flow FERT has been used as an independent tool for monitoring the execution of salt dilution tests and have been executed by means of an array of 16 underwater electrodes ( 14 on the canal bottom and 2 on his sides). The electric cable has been 5 anchored on the canal bottom by means of appropriate weights and the position of each electrode together with the shape of the section has been measured. An example of the electrodes disposition scheme for the test site and a picture of the array is reported in Fig. 5.

The electric cable has been connected to an AC acquiring device (CIT Iridium Italy

10 s.a.s.) injecting a sinusoidal current at $916 \mathrm{~Hz}$. The CIT is a very fast acquisition device with 16 bit resolution. Indeed the instrument can execute approximately 20 acquisitions per second (at the selected operative frequency) so that the acquisition of a single tomographic image can be performed in a relatively fast time. A devoted acquisition sequence consisting of a total of 227 quadrupoles (both dipole-dipole and Wenner types)

15 has been used. In this way it is possible to appreciate variations in concentration also for relatively fast transient phenomena. The acquisitions have been performed continuously for about $5 \mathrm{~min}$ after the impulse plume has been injected in the canal. The time required for the acquisition of a single image is of the order of $30 \mathrm{~s}$ for the experimental setup of this study, including also saving the file and starting up the new measure-

20 ment, therefore the total number of processed images, during the passage of the salt plume, is 9. Data have been inverted by means of an on purpose designed software (NES Electric Arbitrary 2-D Closed Geometry by Andrea Borsic) which is based on a damped least squares inversion algorithm.

A representation based on the relative difference in electric resistivity (ER) among

25 the several images has been adopted in the following. Reference was made to the "clear water" condition by subtracting the resistivity distributions obtained at each time step to a reference image of the canal water measured before the slug injection (ER of $58 \Omega \mathrm{m}$ coherently corresponding to the inverse of the directly measured $\mathrm{EC}$ ). In

10043

this way the passage of the salt plume is expected to provide an overall reduction in resistivity (increased concentration of the salt plume) over the images. Indeed ER is the inverse of EC, so that symmetrical considerations can be made in respect to his behaviour with increasing salt concentration. The same laboratory calibration curve 5 used for the salt dilution method has been later used to convert the resistivity maps in salt concentration maps.

\section{Results and discussion}

The $\mathrm{NaCl}$ curve of the direct sampling with the adopted multi-sampling system is reported in Fig. 6; given the equations reported in the previous paragraph, this curve 10 highlight a discharge equal to $0.46 \mathrm{~m}^{3} \mathrm{~s}^{-1}$. For convenience of comparison with the results of cross-flow FERT data have been converted in ER and an indication of the average time of acquisition of each tomographic image is also reported in the same figure.

The results of some acquired images during the passage of the salt plume are instead presented in Fig. 7; some of the images, with very similar ER distribution, have been suppressed (dashed lines in Fig. 6) for easiness of visualization. In these images the ER difference with respect to the "clear water" condition (image at time $25 \mathrm{~s}$ ) are reported. Images are very clear in the recognition of the passage of the plume, identified with a strong resistivity reduction. This reduction is quite homogeneous in the 20 early times, in correspondence to the higher salt concentration in the transient plume, but appears more concentrated in some zones of the canal in late times. Noticeably the left side of the reconstructed resistivity image (which is upstream the canal curve) appears not affected by the passage of the plume. This has been also observed on site by visual inspection of the passing plume. The imaged reduction in resistivity shows

25 average values around about $25 \Omega \mathrm{m}$, even if localized higher values are present in the map. These values seems little lower with respect to the direct sampled curve which 
instead reports a peak of about $40 \Omega$ m reduction with respect to the canal "clear water" resistivity (Fig. 6).

The resistivity images acquired have been then interpreted in order to extract quantitative information about the salt concentration. Such interpreted data are reported in

5 Fig. 8 for the same sampling intervals of Fig. 7 and in Fig. 9 in a 3-D representation. The salt plume is clearly evidenced in both images. However, with respect to the previous images, some localized peaks in concentration appear more evidently related to the laminar flow of the canal. Particularly in the 3-D visualization it appears clear that the "coda" of the plume are located along the banks of the canal. Indeed the velocity of

10 flow varies from zero at the walls to a maximum along the center. This reflects in two main concentration peaks located on both sides of the measuring section and only one of them appears correctly sampled by the direct method since the sampling grid has been placed nearer to the left downstream bank (Fig. 4).

By extracting mean and standard deviation values of concentration in every tomo-

15 graphic image it is also possible to estimate a time-concentration curve also from geophysical measurements. This interpretation is reported in Fig. 10 and compared to the one obtained from direct measurements. The mass balance of the injected salt extracted from the two evaluations (i.e. direct sampling and cross-flow FERT) partially differs, the mean value of cross-flow FERT data report globally a lower concentration peak. There are several reasons to explain the observed differences:

- the concentration extracted from cross-flow FERT is an integral concentration over a measuring time (30 s) which is higher than the one used for direct sampling (5s); this will probably result in a reduced peak value given the fast phenomenon in observation;

- the reduced peak concentration observed by cross-flow FERT may be also related to the smoothing of the inversion algorithm adopted which does not allow for too sharp variations in concentration; it must indeed be noted the increased dimensions of standard deviation error-bars near the peak of the plume with respect

10045

to a more homogeneous situation towards the end of it; this implies that when the concentration distribution within the section is sharp the inverse solution has increased variability;

- cross-flow FERT conversely images the whole section of the canal (included the left bank where there appear to be a reduced concentration area) in respect to the direct sampling technique and therefore seems globally more reliable;

- direct sampling can be affected by localized high concentration points which could influence the overall estimate; data of cross-flow FERT seems indeed to be better in agreement if the maximum concentration value is considered (dashed red line in Fig. 10).

In order to assess the likelihood of this last reason, a comparison between direct sampling and cross-flow FERT been performed, over the same sampling area of the canal. In this respect Fig. 11 reports an image of the plume in correspondence of the sampling grid at the time of passage of the main concentration peak. It can be noted that most of the spilling points appears located near to high concentration peaks and therefore the average concentration curve may be biased towards higher values. Providing similar images preliminary to the design of the sampling grid could be therefore a strong help in establishing the most correct measurement protocol.

\section{Conclusions}

Direct sampling of the $\mathrm{NaCl}$ plume from a slug-injection salt dilution test and geophysical imaging of the same salt plume, by means of cross-flow fast electric resistivity tomography (FERT), have been compared in this work. Direct sampling has been performed with a multisampling optimization in the downstream section, obtaining an average value over the sampled stream section, using a contemporary water sampling; geophysical data have been acquired and interpreted independently. 
Results shows that the reconstructed curve from cross-flow FERT seems affected from an overall lower sensitivity in respect to the peak passage of the plume and therefore mass balance estimations based on these data cannot be completely reliable. Nevertheless cross-flow FERT has provided a good qualitative visualization of the pas5 sage of the plume in the imaged section and, since the knowledge of tracer distribution in the cross-section is very important for a correct location of sampling points, can be used as a preliminary control in order to establish the best position for accurate discharge measurements by means of the direct sampling method.

Following this first visualization, a sampling optimization in the downstream sampling 10 section, using a multisampling technique, can be strongly recommended. This method, sampling the canal water in different points of the cross section, by means of a contemporary water picking up, can indeed optimize the quantitative detection and result in more reliable discharge estimates.

Acknowledgements. This research has been partially funded in the framework of a research 15 project between the Agricultural Management of Piedmont Region and the Earth Science Department of Università degli Studi di Torino. Authors are indebted with Paolo Clemente, Giovanna Dino, Diego Franco, Francesco Marzano and Sabrina Bonetto for their help in the execution of the field tests.

\section{References}

20 Clemente, P., De Luca, D. A., Dino, G. A., and Lasagna, M.: Water losses from irrigation canals evaluation: comparison among different methodologies, Geophys. Res. Abstr., EGU20139024, EGU General Assembly 2013, Vienna, Austria, 2013.

Day, T. J.: On the precision of salt dilution gauging, J. Hydrol., 31, 293-306, 1976.

Drost, J. W.: Single-Well and Multi-Well Nuclear Tracer Techniques - a Critical Review, Tech-

25 nical Documents in Hydrology, International Hydrological Programme, 96, UNESCO, Paris, 1989.

10047

Fangary, Y. S., Williams, R. A., Neil, W. A., Bond, J., and Faulks, I.: Application of electric resistance tomography to detect deposition in hydraulic conveying systems, Powder Technol., 95, 61-66, 1998.

Gees, A.: Flow measurement under difficult measuring conditions: Field experience with the salt dilution method, in: Hydrology in Mountainous Regions I. Hydrological Measurements; The Water Cycle, edited by: Lang, H. and Musy, A., IAHS Publ., 193, 255-262, 1990.

Kalbus, E., Reinstorf, F., and Schirmer, M.: Measuring methods for groundwater - surface water interactions: a review, Hydrol. Earth Syst. Sci., 10, 873-887, doi:10.5194/hess-10-873-2006, 2006.

10 Kumar, B. and Nachiappan, R. P.: Estimation of alluvial aquifer parameters by a single-well dilution technique using isotopic and chemical tracers: a comparison, in: Tracers and Modelling in Hydrogeology, IAHS Publ. 262, edited by: Dassargues, A., IAHS Press, Wallingford, 53-56, 2000.

Lucas, G. P., Cory, J., Waterfall, R. C., Loh, W. W., and Dickin, F. J.: Measurement of the solids

15 volume fraction and velocity distributions in solids-liquid flows using dual-plane electrical resistance tomography, Flow Meas. Instrum., 10, 249-258, 1999.

Moore, R. D.: Slug injection using salt in solution, Streamline Watershed Management Bulletin, 8, 1-6, 2005.

Perotti, L., Clemente, P., De Luca, D. A., Dino, G. A., and Lasagna, M.: Remote sensing and hydrogeological methodologies for irrigation canal leakage detection: the Osasco and Fossano test sites (Northwestern Italy), Geophys. Res. Abstr., EGU2013-5705, EGU General Assembly 2013, Vienna, Austria, 2013.

Radulović, M., Radojević, D., Dević, D., and Blečić, M.: Discharge calculation of the spring using salt dilution method - application site Bolje Sestre Spring (Montenegro), available at: http:

25 //balwois.com/balwois/administration/full_paper/ffp-1257.pdf (last access: 24 July 2013), 2008.

Rantz, S. E.: Measurement and Computation of Streamflow: Volume 1. Measurement of Stage and Discharge, US Geological Survey Water-Supply Paper 2175, US Department of the Interior, US Government Printing Office, Washington, DC, 1982.

30 Sambuelli, L. and Comina, C.: Fast ert to estimate pollutants and solid transport variation in water flow: a laboratory experiment, B. Geofis. Teor. Appl., 51, 1-22, 2010. 
Sambuelli, L., Lollino, G., Morelli, G., Socco, L. V., and Bidone, L.: First experiments on solid transport estimation in river-flow by fast impedance tomography, VIII EEGS meeting, 815 September, cd-rom 4 pp., Aveiro, Portugal, 2002.

Tapp, H. S. and Wilson, R. H.: Developments in low-cost electrical imaging techniques, Process

5 Contr. Qual., 9, 7-16, 1997.

Tazioli, A.: Experimental methods for river discharge measurements: comparison among tracers and current meter, Hydrolog. Sci. J., 56, 1314-1324, 2011.

Xie, C. G., Reinecke, N., Beck, M. S., Mewes, D., and Williams, R. A.: Electrical tomography techniques for process engineering applications, Chem. Eng. J., 56, 127-133, 1995.

10 Wang, M. and Cilliers, J. J.: Detecting non-uniform foam density using electrical resistance tomography, Chem. Eng. Sci., 54, 707-712, 1999.

Warsito, W. and Fan, L. S.: Measurement of real-time flow structures in gas-liquid and gasliquid-solid flow systems using electrical capacitance tomography (ECT), Chem. Eng. Sci., 56, 6455-6462, 2001.

15 Yang, W. Q. and Liu, S.: Role of tomography in gas/solids flow measurement, Flow Meas. Instrum., 11, 237-244, 2000.

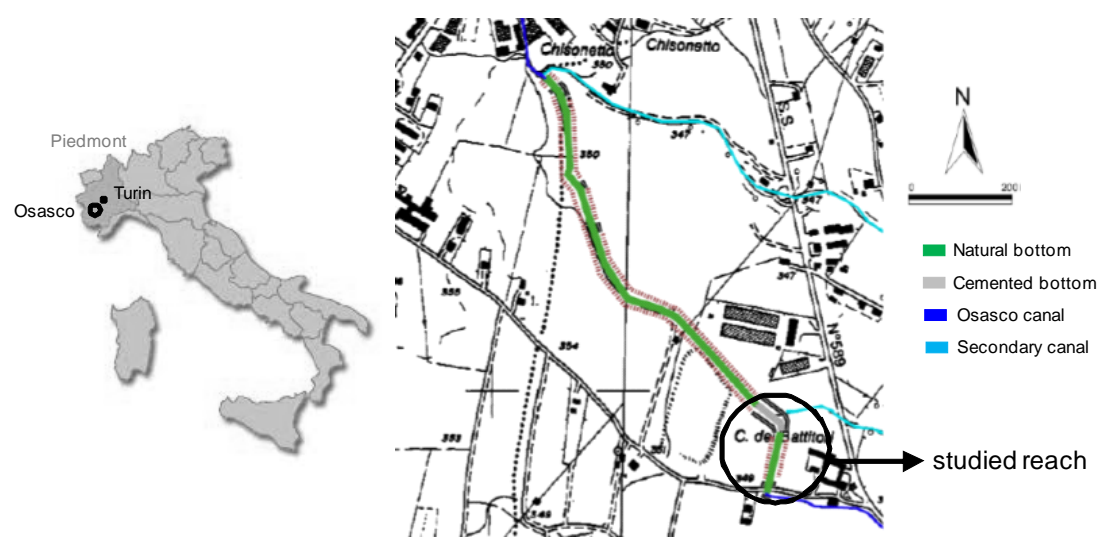

Fig. 1. Geographical location of the test canal (inlet) and a more detailed view in the proximity of the test site. 
slug injection

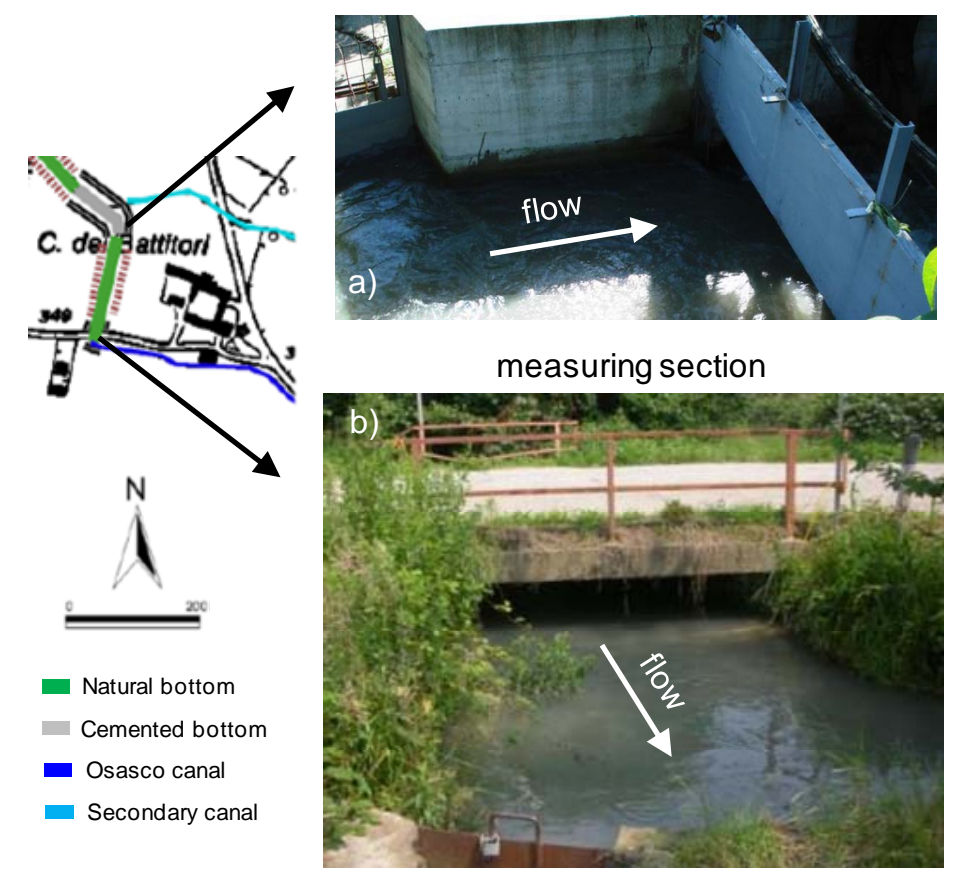

Fig. 2. Tested canal reach: (a) injection point at the end of a cemented weir and (b) measuring section, under a small road bridge and before a canal curve.

10051

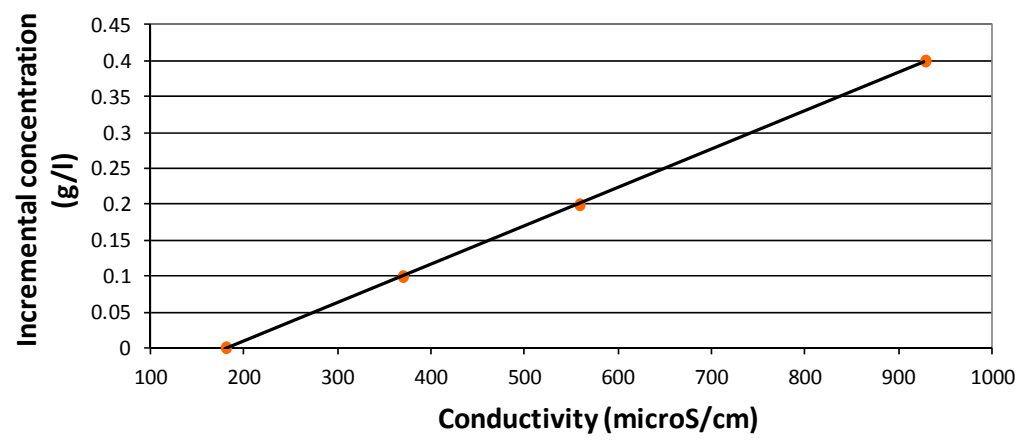

Fig. 3. Calibration curve for converting EC measured data to concentration values with reference to the natural water electrical conductivity $\left(170 \mu \mathrm{S} \mathrm{cm}^{-1}\right)$. 


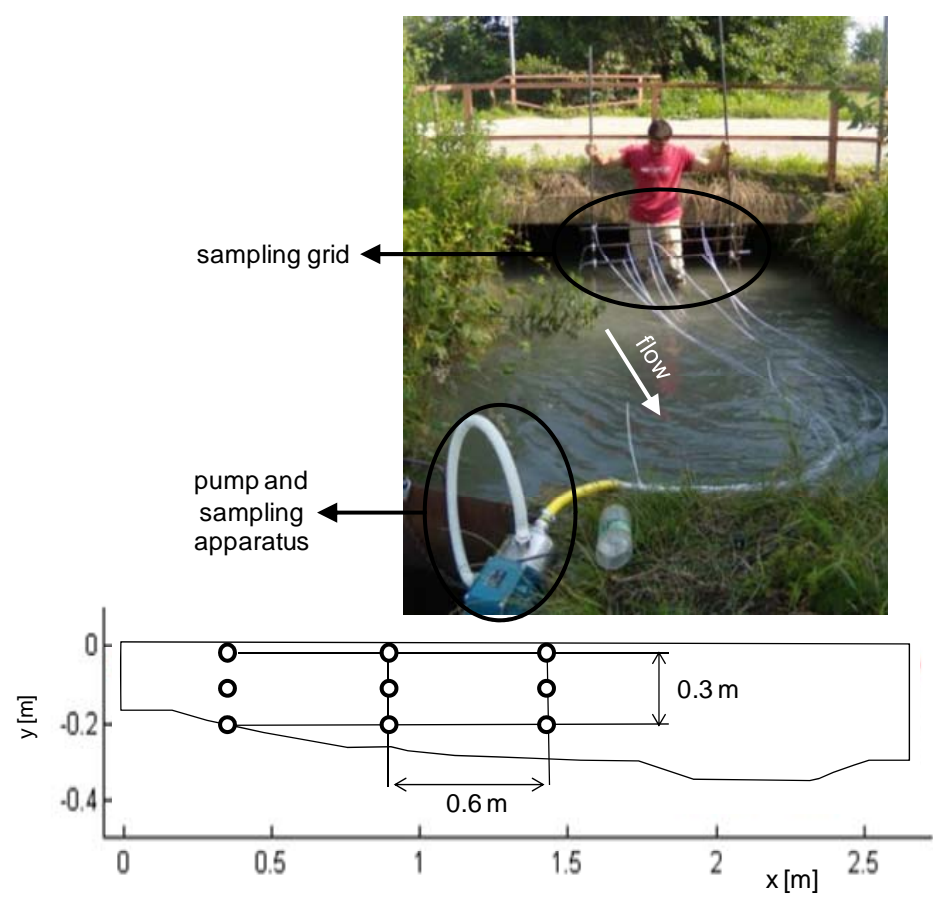

Fig. 4. Multi-sampling system with details of the sampling grid (black circles are water spilling points) and of the pumping apparatus; the below section is seen from up-stream.

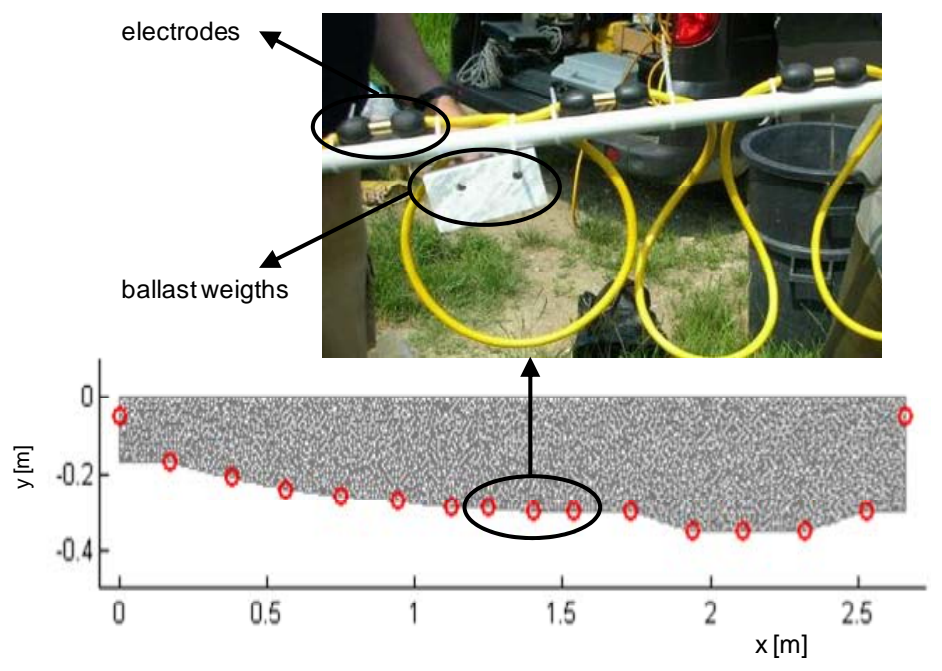

Fig. 5. Electrodes disposition for cross-flow FERT: images of the electrodes and the anchoring system (top) and of the mesh used for the inversion (bottom), the below section is seen from up-stream. 


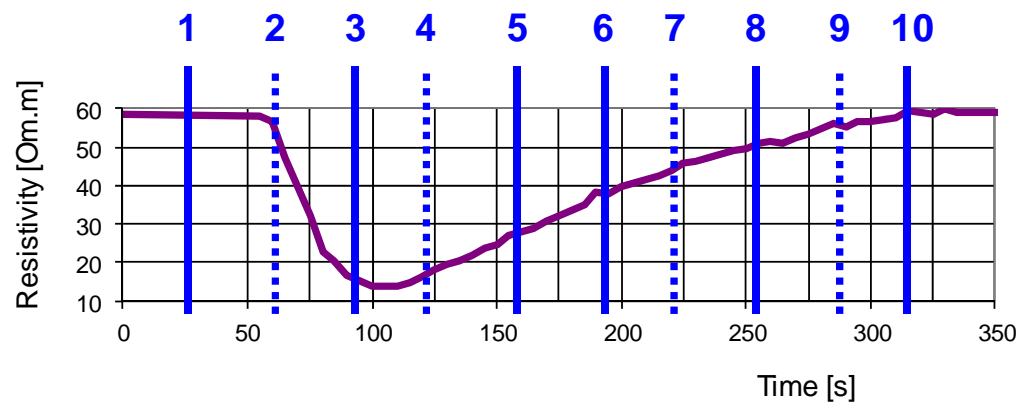

Fig. 6. Time-resistivity curve determined with the multisampling apparatus and indication of the number and time of execution of the cross-flow FERT images presented in Figs. 7 and 8 (full lines).

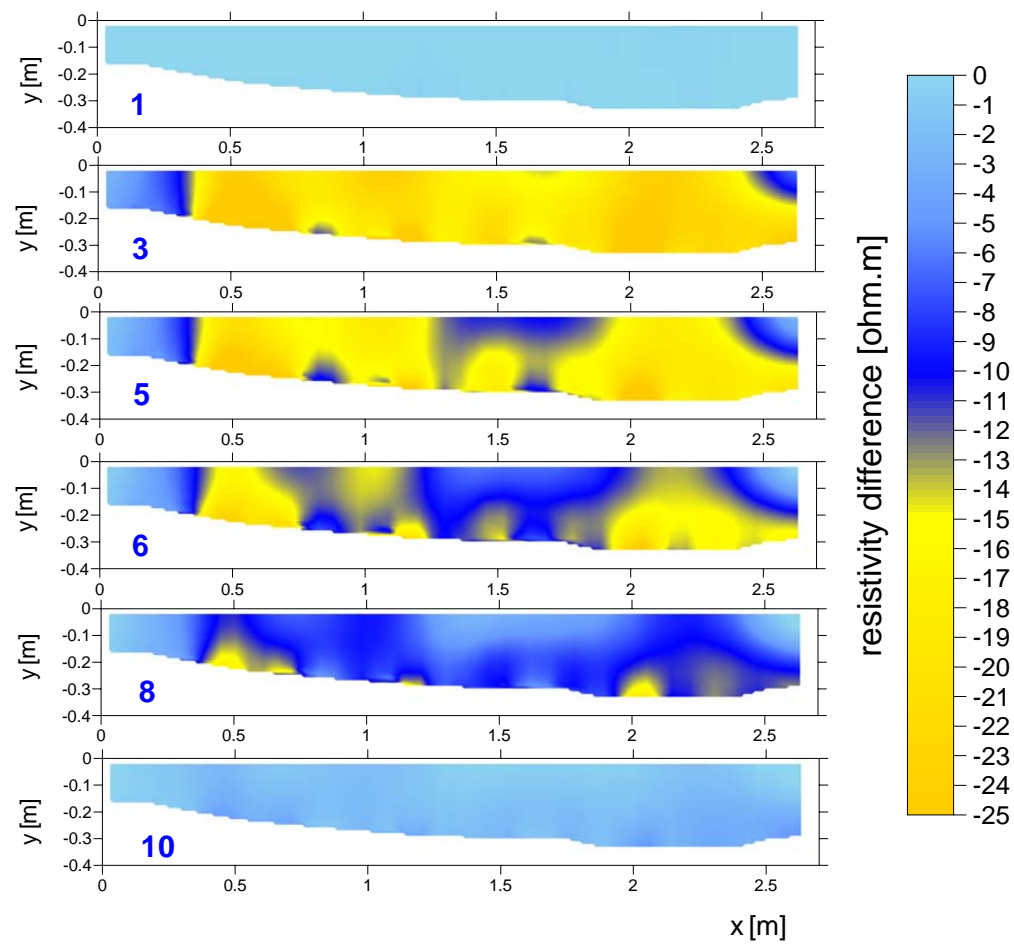

Fig. 7. Electric resistivity differences in the imaged section for increasing times, image number with reference to Fig. 6, seen from up-stream. 

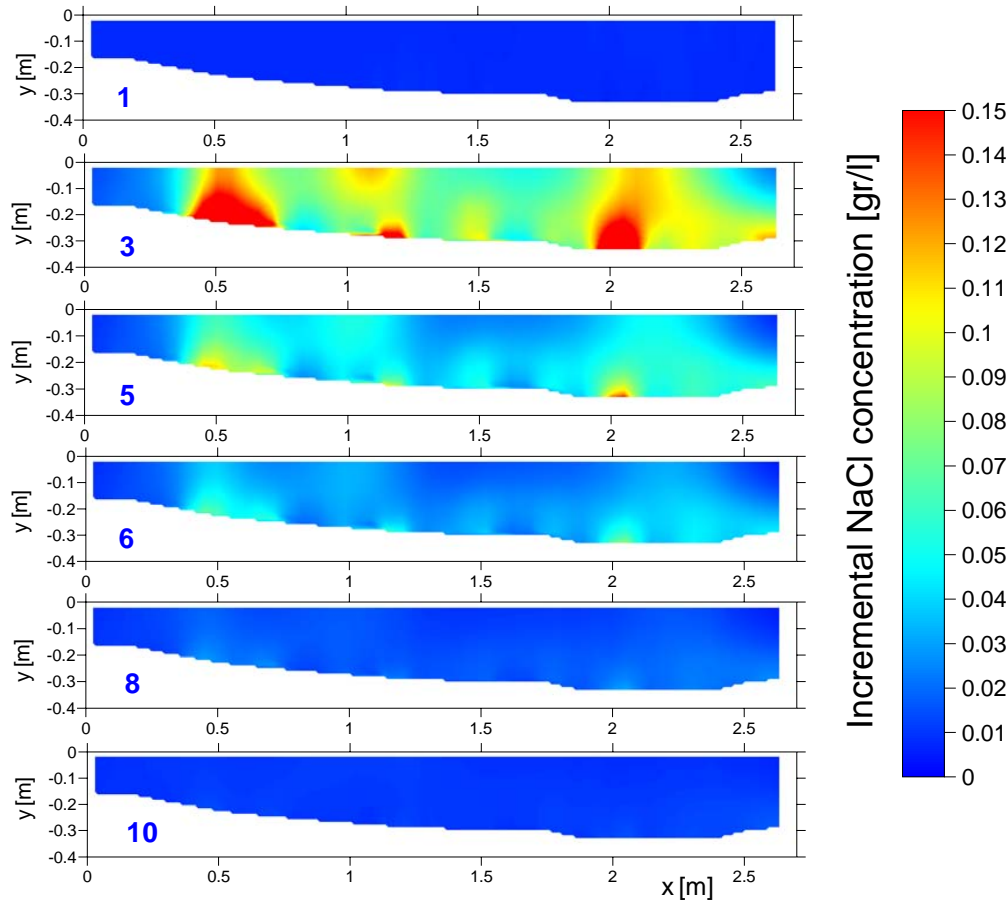

Fig. 8. Incremental concentrations in the imaged section for increasing times, image number with reference to Fig. 6 , seen from up-stream.

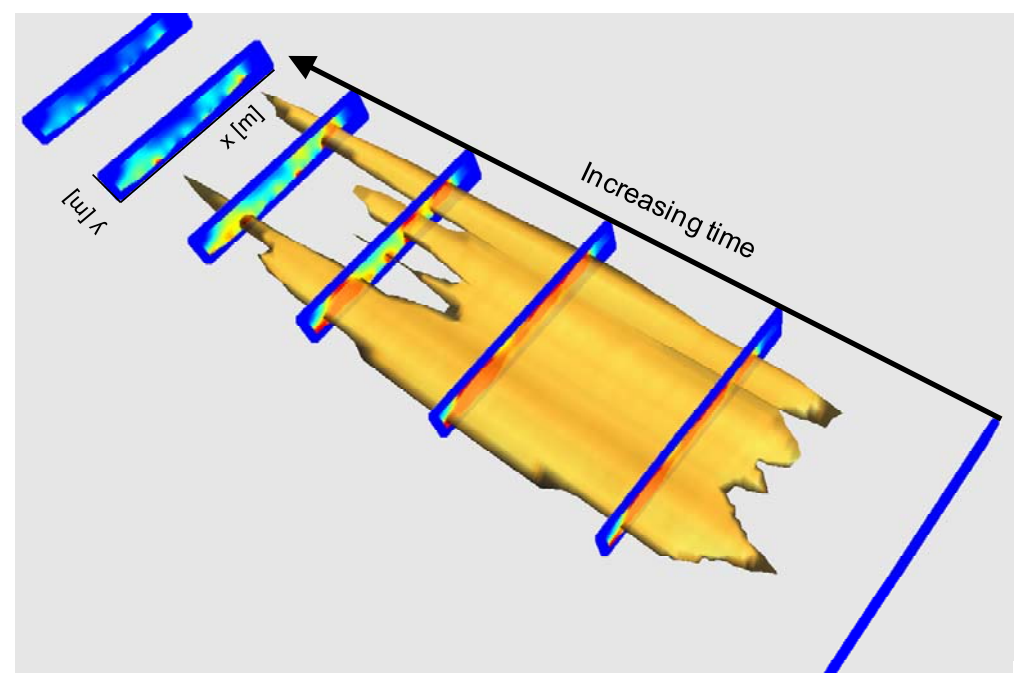

Fig. 9. 3-D visualization of the passage of the salt plume in the studied canal section. 


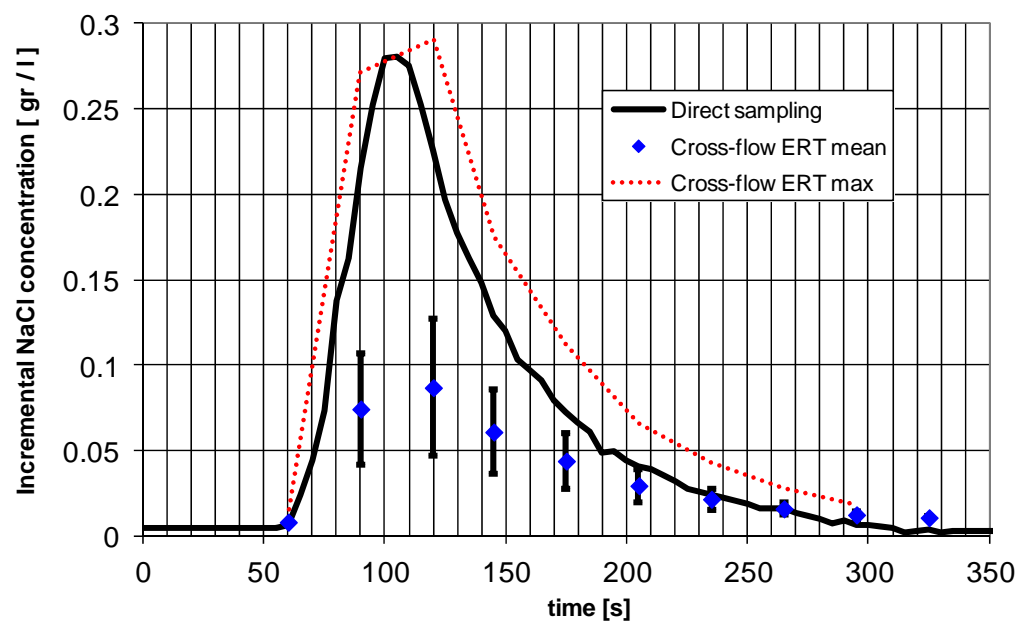

Fig. 10. Comparison of direct sampling and cross-flow FERT obtained concentration curves; the dashed red line refers to the maximum concentration value determined from cross-flow FERT in the area of the canal reported in Fig. 11.

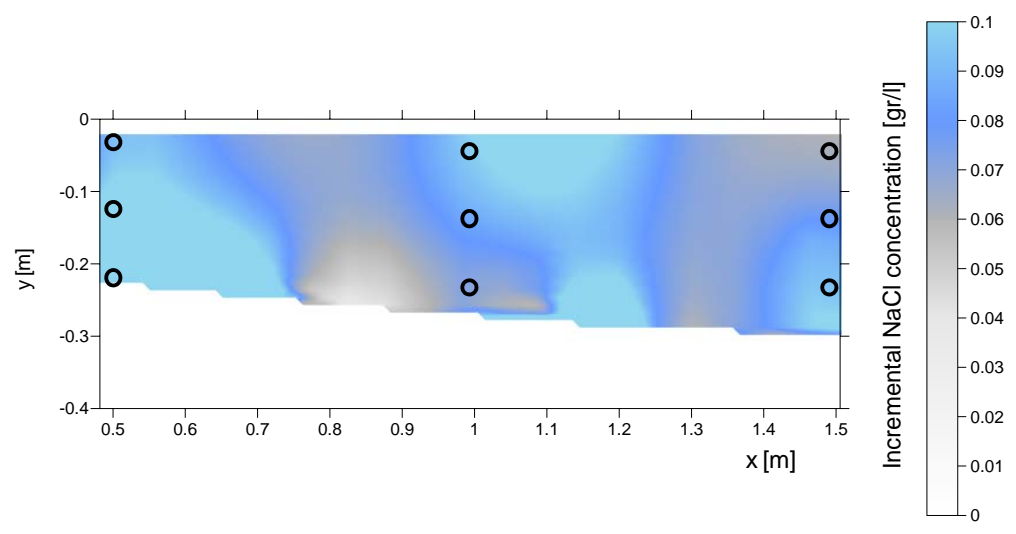

Fig. 11. Comparison of direct sampling (black circles are water spilling points) and cross-flow FERT over the same sampling area at the time of passage of the main plume. 